\title{
Edwin Morgan: um poema e cinco versões
}

\author{
Almiro Pisetta; Christianne Ritchie; John Milton; \\ Telma Franco e Virna Teixeira
}

One Cigarette

No smoke without you, my fire.

After you left,

your cigarette glowed on in my ashtray

and sent up a long thread of such quiet grey

I smiled to wonder who would believe its signal

of so much love. One cigarette

in the non-smoker's tray.

As the last spire

trembles up, a sudden draught

blows it winding into my face.

Is it smell, is it taste?

You are here again, and I am drunk on your tobacco lips.

Out with the light.

Let the smoke lie back in the dark.

Till I hear the very ash

sigh down among the flowers of brass

I'll breathe, and long past midnight, your last kiss. 
PISETTA, A.; RITCHIE, C.; MILTON, J.; FRANCO, T.; TEIXEIRA, V. Edwin Morgan:...

Edwin Morgan, o autor desse belo e intrigante poema, é um dos poetas mais queridos e respeitados da Escócia - foi eleito o Glasgow's First Poet Laureate em 1999 e sua tradução de Phaedra, para o Scots, Ihe rendeu o prestigioso Weidenfeld Prize for Translation, em 2001. Um ano antes ele havia recebido da rainha Elizabeth a cobiçada Queen's Gold Medal for Poetry. É também um prolífico tradutor-poeta. Em seu livro Collected Translations, encontramos traduções de grandes poetas russos, italianos, franceses e alemães, além dos brasileiros Edgard Braga, Pedro Xisto e Haroldo de Campos. Apesar de tudo isso, Morgan continua pouco conhecido no Brasil. Divulgar seu nome e incitar os leitores a conhecer um pouco mais de sua obra são alguns de nossos objetivos.

Nas próximas páginas, o leitor encontrará um breve relato sobre a vida do poeta, cinco versões comentadas do poema "One Cigarette" realizadas por cinco pessoas de formações relativamente diferentes, mas unidas pelo amor à poética de Edwin Morgan, e uma pequena relação das obras de Morgan e sobre Morgan. Slip out of darkness, Edwin, it is time. '

Oator

Edwin Morgan nasceu na Escócia em 27 de abril de 1920. Quando ouvimos falar em Escócia é comum vir-nos à mente imagens algo romantizadas, ou irreais, devido à distância ou ao mero desconhecimento. Alguns talvez pensem na herança celta, outros nos famosos uísques, outros nos saiotes kilt ou na gaita-de-foles, ou ainda nos fascinantes lagos, conhecidos localmente como lochs, e no belo litoral recortado por penhascos vertiginosos. Porém, há algo que nos escapa quase inteiramente e que, contrariamente a algumas imagens românticas, é bem real: o gosto dos escoceses 
pela poesia. Não é preciso marcar hora nem local - se você estiver em Glasgow, por exemplo, pode ser surpreendido na cantina, no pub ou no café por algum poeta amador que se levanta de repente e declama poema próprio ou de autor consagrado. Declamar faz parte da cultura escocesa, é hábito praticado até pelos mais tímidos. E o tímido Edwin Morgan, natural de Glasgow, talvez seja o poeta mais declamado da Escócia. Seus versos estão entre os mais estudados nas escolas e ele é certamente o poeta mais querido: Morgan's work is taught extensively and for one very good and central reason: its appeal to young people. ${ }^{2}$

Esse forte apelo sobre o público, especialmente o público jovem, em parte é devido a seu arrojo. Morgan é tímido, sim, mas arrojado - disposto a mergulhar em temas de seu interesse e imbuir-se neles de maneira surpreendente. Por ter interesses tão amplos, alguns críticos chegaram a considerá-lo superficial, quando na verdade ele é versátil - não adota apenas um estilo. Como observa Christianne Ritchie em Edwin Morgan: o poeta do presente e do futuro, no começo da carreira o poeta esbanjou exuberância lingüística; depois, tornou-se mais intimista e inovador - realizando experiências sonoras ao ter contato com o formalismo russo e com o movimento concretista -, brincou com notícias de jornais e com os avanços tecnológicos, retratou o cotidiano de Glasgow e, por fim, as próprias vivências.

Versátil também nas atividades às quais se dedicou ao longo da vida, Morgan foi professor, dramaturgo, editor, crítico literário e tradutor. É interessante notar que também na tradução ele não usa uma fórmula fixa: embora a princípio tenha seguido rigorosamente as lições de Ezra Pound (com o "make it new") e tentado criar novos poemas na língua de chegada, Morgan logo passou a adotar parâmetros próprios e a tratar cada poema da maneira como acreditava ser mais fiel ao tom do original - contrapondo sonoridade a literalidade, ritmo a forma etc. Em suma, ele procurava ser fiel ao léxico sem, contudo, perder de vista o tom. 
PISETTA, A.; RITCHIE, C.; MILTON, J.; FRANCO, T.; TEIXEIRA, V. Edwin Morgan:...

Filho único de uma família de classe média, ainda criança Morgan já escrevia poemas e elaborava listas com suas palavras prediletas, escolhidas pela sonoridade. Cresceu ouvindo em casa o sotaque típico e o vocabulário considerado culto naquela região, semelhante ao inglês britânico, mas pontuado por expressões e palavras em Scots - idioma regional, considerado uma variante escocesa do inglês. Aliás, Morgan lança mão do Scots tanto na obra poética quanto na tradutória. Ao traduzir os poemas futuristas de Maiakóvski, ele preferiu vertê-los ao Scots a vertêlos ao inglês por acreditar que, entre as duas línguas, o Scots acomodava melhor a inventividade e o coloquialismo da língua russa.

Morgan ingressou na faculdade de Letras em 1937, aos 17 anos, depois de desistir do curso de pintura da Escola de Artes. Mas a imagem permaneceria uma referência constante em sua poesia, como se pode observar especialmente na série Instamatic Poems, de 1972.

Entre 1940 e 1946 seu curso universitário foi interrompido devido à Segunda Guerra Mundial. Pacifista, Morgan acabou se alistando como auxiliar de enfermagem por acreditar que serviria melhor à causa fazendo algo pelos compatriotas feridos. A experiência da guerra $\mathrm{o}$ marcou tão profundamente que foram precisos 30 anos para que ele refletisse sobre ela. Suas impressões e memórias do período foram publicadas em 1977, em The New Divan.

Em 1947, terminada a graduação, Morgan tornou-se professor assistente da Universidade de Glasgow. Passou a professor titular do Departamento de Inglês em 1950 e ali permaneceu até 1980, quando se aposentou. A segurança da vida acadêmica lhe permitiu organizar sua carreira poética, e em 1952 ele publicou The Vision of Cathkin Braes.

Entretanto, essa mesma carreira acadêmica que o libertou para dedicar-se à poesia também o tolheu na vida pessoal, pois 
ele se sentia socialmente obrigado a ocultar sua homossexualidade. É preciso lembrar que até 1980 o homossexualismo era considerado crime na Grã-Bretanha. Morgan só tornou pública sua homossexualidade em 1990, ao completar 70 anos. O cuidado em manter segredo fez com que ele evitasse ser explícito em relação ao objeto amado em seus poemas, omitindo referências a nomes e a partes do corpo e mascarando sinais. $\bigcirc$ que "pode ser dito" é de certa forma esmerilhado para poder conter o que "não pode ser dito". Nessa fase da sua poesia a ambigüidade era uma constante.

Em 1990, após revelar sua homossexualidade, Morgan disse numa entrevista que a ambigüidade era proposital: I knew that when I was writing (the poems) that they must be ambiguous and that comes in many cases, I suppose, from a kind of apprehension, more than anything else. ${ }^{3}$ Com o passar do tempo, entretanto, foi deliberadamente se tornando mais explícito até que, em 1991, já livre da auto-imposta censura, publicou Holding Hands Among the Atoms, que exibe uma franqueza surpreendente. Já o livro The Second Life, publicado em 1968, de onde o poema "One Cigarette" foi extraído, é permeado pela dubiedade, pela elipse, pelos subterfúgios.

A seguir, os cinco participantes deste trabalho coletivo apresentam e comentam suas versões do poema "One Cigarette". 
PISETTA, A.; RITCHIE, C.; MILTON, J.; FRANCO, T.; TEIXEIRA, V. Edwin Morgan:...

\title{
Os tradutores e suas versões comentadas
}

\begin{abstract}
Almiro Pisetta
Tradutor, professor de Tradução e Literatura Inglesa no Centro Universitário Unibero e ex-professor de Literatura Inglesa e Norte-americana na USP, é bacharel em Língua e Literatura Inglesas pela Duquesne University de Pittsburgh, mestre em Lingüística Aplicada pela USP e doutor em Literatura Inglesa e Norte-americana pela USP. Entre suas várias traduções já publicadas, destacam-se O Senhor dos Anéis (Martins Fontes), em parceria com Lenita Esteves e C.S. Lewis - o mais relutante dos convertidos (Editora Vida), em parceria com Fernando Dantas.
\end{abstract}

O poema descreve a celebração ritualística de uma espécie de súbita e intensa saudade amorosa. A pessoa amada acaba de sair, e sua ausência está presente no cigarro deixado aceso num cinzeiro de latão. $\bigcirc$ amante, que não fuma, sente-se impelido a anunciar e ritualizar seu amor. De luz apagada, recebendo no rosto a metonímica fumaça, ele faz amor "meia-noite adentro" e até o último suspiro da brasa sob a cinza vai sorvendo o último beijo no/do cigarro.

Algumas observações:

- $\bigcirc$ primeiro verso parece conter uma ambigüidade. Além de aludir ao provérbio There's no smoke without fire, também se refere ao hábito de fumar, pois a palavra smoke pode ser usada informalmente para referir-se ao cigarro. Daí a escolha do termo "fumo" na tradução.

- "Um cigarro / no cinzeiro de um não-fumante." Constatação particularmente significativa, dada a intolerância ao fumo dos tempos atuais. Mais significativa ainda é a transformação do cigarro na pessoa amada, por metonímia. 
- A frase I am drunk on your tobacco lips foi traduzida como "eu bebo do fumo dos teus lábios". É óbvia a intenção de sugerir a idéia de "bêbado" em "bebo do".

Há no poema de Edwin Morgan um predomínio de sibilantes, saliente sobretudo na terminação dos três últimos versos. $\bigcirc$ som sibilante parece estar ligado à fumaça do cigarro. Na tradução também aparecem muitas sibilantes, mas sua concentração maior se dá no início da segunda parte do poema.

\section{UM CIGARRO}

Sem você não há fumo, fogo meu.

Você se foi, e seu cigarro ficou aceso em meu cinzeiro, exalando um longo fio de silêncio cinza.

Eu sorri indagando quem leria tal sinal de tanto amor. Um cigarro no cinzeiro de um não-fumante.

Enquanto a última espiral trêmula sobe, um sopro súbito sopra sua curva contra a minha cara.

Será o cheiro? Será o sabor?

Você está aqui de novo, e eu bebo do fumo dos teus lábios.

Apague-se a luz.

Que a fumaça se deite no escuro.

Até eu ouvir a própria brasa

exalar o suspiro final entre a flores de latão, vou sorver, meia-noite adentro, o seu último beijo. 
PISETTA, A.; RITCHIE, C.; MILTON, J.; FRANCO, T.; TEIXEIRA, V. Edwin Morgan:...

\section{Christianne Ritchie}

Coordenadora pedagógica da Seven Idiomas, Christianne obteve grau de mestre pela USP com a dissertação Edwin Morgan: o poeta do presente e do futuro, sob orientação do Prof. Almiro Pisetta. Antes e durante a elaboração de seu trabalho, ela viajou para a Escócia, conheceu o poeta pessoalmente e visitou-o em sua casa, que ela descreve como inteiramente forrada de livros. Apaixonada pelo poeta e sua obra, por meio de sua dissertação escrita com estilo aconchegante e amoroso, Chris faz com que vislumbremos pontos cruciais da poética de Morgan e nos incita a querer saber mais sobre ele.

O lirismo de "One Cigarette" é intenso. Como um cigarro é capaz de proporcionar imenso prazer em apenas alguns minutos; condensa em suas 17 linhas uma das mais inesperadas imagens do amor: um cigarro no cinzeiro do não-fumante. E esta imagem banal, talvez até nauseante para um não-tabagista e sobre a qual poderia se pensar que apenas quem não fuma compreenderia em toda sua proporção, torna-se bela, delicada e sensual a todos nos versos de Morgan. Poeta-gênio de ousadia e originalidade que dá voz e poder de ordem e de invocação a seres imaginados, objetos, animais, defuntos famosos, heróis urbanos e da ficção científica, também retrata suas lembranças de momentos íntimos alternando puro lirismo com sensualidade explícita.

Minha versão para "One Cigarette" procurou manter a mesma imagem do cigarro aceso queimando enquanto a cinza vai caindo devagar no cinzeiro de latão com flores em relevo sob o olhar embriagado do amante consumido pelo amor; ele que também se deixou queimar e agora tenta descansar imóvel desejando o retorno do amado que partiv e o deixou ainda ardendo na cama. Esse desejo queima e dele restará apenas cinza - aqui as flores do cinzeiro, assim como as cinzas, remetem à morte, ao fim; mas por algumas horas o cheiro e o gosto do cigarro permanecerão no 
corpo e no quarto do amante e a presença do amado será revivida até bem depois da meia-noite, ou seja, até que ele possa dormir e retomar sua vida na manhã seguinte.

Conservei a simplicidade do vocabulário, excluindo a escoIha de Morgan por spire, um tanto hermética, que além das imagens a que remete, há a rima com fire, por isso optei por espiral para rimar com sinal; do mesmo modo procurei recompor as aliterações e rimas. Exceção à simplicidade foi a preferência por ébrio em vez de embriagado pelo número de sílabas e a inversão com o verbo, pois assim me soou melhor. Outro momento em que o coloquial dá lugar a algo mais formal é no verso "Fora com a luz"; apesar de certa formalidade, foi a melhor solução que encontrei para manter o impacto da agressividade de out with the ligh do original. 
PISETTA, A.; RITCHIE, C.; MILTON, J.; FRANCO, T.; TEIXEIRA, V. Edwin Morgan:...

\section{UM CIGARRO}

Não há fumaça sem você, meu fogo.

Depois que saiu, seu cigarro ficou aceso em meu cinzeiro, emitindo um fio de fumaça tão silencioso que sorri ao pensar quem acreditaria ser este sinal de tanto amor. Um cigarro no cinzeiro do não-fumante.

A última espiral tremula e uma súbita corrente de ar a sopra em meu rosto.

Isso é cheiro, é gosto?

É você de volta e ébrio estou nos seus lábios de tabaco.

Fora com a luz.

Deixe a fumaça descansar no escuro.

Até que eu ouça a cinza

expirar entre as flores em relevo

vou respirar, bem depois de meia-noite, seu último beijo. 


\section{John Milton}

Tradutor, professor de Língua Inglesa e Literatura Inglesa e Norte-americana na USP, John é bacharel em Literatura Inglesa pela University of Wales, mestre em Lingüística Aplicada pela PUC, doutor e livre-docente em Literatura Inglesa e Norte-americana pela USP. Entre suas traduções já publicadas destaca-se a antologia de poemas de John Keats Nas invisíveis asas da poesia (lluminuras), em parceria com Alberto Marsicano. É autor de Tradução: teoria e prática (Martins Fontes), O clube do livro e a tradução (Edusc) e Imagens de um mundo trêmulo (Editora Hedra), entre outras obras.

"One Cigarette" é um poema que mostra Morgan usando os códigos eróticos.

Para mim, a imagem do cigarro, do spire, do glowing, do sent up, apontam para o elemento erótico, a ereção do visitante; e sigh down a detumescência pós-coito. Então, ash seria o sêmen, flowers of brass, os testículos.

Continuando a quebrar esse poema-código, imaginando que o eu lírico seria mesmo masculino, o tray, bandeja, um receptáculo, nesse caso talvez o ânus, logo trocado por sexo oral, quando o spire aparece em frente da cara do poeta. Lips é sempre ambíguo, podendo-se referir aos lábios da vagina e também, neste caso, os do ânus.

É claramente um poema ao amor homossexual, escrito em códigos que são possíveis de serem interpretados. 
PISETTA, A.; RITCHIE, C.; MILTON, J.; FRANCO, T.; TEIXEIRA, V. Edwin Morgan:...

\section{UM CIGARRO}

Não há fumaça sem ti, meu fogo.

Tu foste,

e teu cigarro ficou incandescente em meu cinzeiro

e ergueu um fio tão cinza, silente e teso

que sorri, pensando quem veria neste sinal

tanto amor. Um cigarro

no cinzeiro do não-fumante.

Enquanto a última torre

sobe tremulante, uma brisa súbita

joga sua espiral em meu rosto.

É cheiro ou gosto?

És aqui de novo e me embriago em teus lábios de tabaco.

Apaguem as luzes

e a fumaça deite na escuridão.

Até eu ouvir a própria cinza

gemer lá no fundo entre as flores de bronze

respirarei, e na madrugada, seu último beijo. 


\section{Telma Franco}

Engenheira química, mestre em Engenharia de Alimentos e pós-graduada em Tradução pela USP.

Ao ler o poema em voz alta, chamou-me a atenção a profusão de "esses": smoke, sent, ashtray, last, past, brass, etc. Julguei que, com isso, o poeta estivesse mimetizando o tragar de um cigarro. Mantendo a idéia de reproduzir as tragadas na escolha das palavras, comecei a pensar naquelas que pudessem me ajudar a reproduzir também as rimas que julgara ter encontrado: fire/spire; astray/grey/tray; face/taste; light/midnight; brass-breathe/last-kiss, entre outras. Era preciso também manter a brincadeira com o provérbio "onde há fumaça, há fogo".

Primeiro tentei obedecer à ordem das rimas do original: spire do oitavo verso rimando com fire do primeiro - literalmente "fogo" ou, invertendo o provérbio, "fumaça" - e anotei tudo que me veio à cabeça com sons semelhantes a fogo e fumaça: logro, jogo, engodo; e escassa, brasa, baça, mortiça, esparsa. Mas logo me convenci de que, como as rimas não seguiam um padrão definido, eu podia tomar a liberdade de distribuí-las noutros pontos. E cogitei rimas para outras sonoridades. Para "aceso" pensei em teso, aqueço, avesso; para "fumo", sumo, lume, gomo, etc.

Fora a distribuição das rimas, acabei tomando outras liberdades. Explico: para mim, a alusão ao amor romântico é evidente. No verso I smiled to wonder who would believe its signal of so much love, o poeta revela que tolera a fumaça que the seria intolerável porque ela provém do cigarro do amado, o que justifica seu sacrifício, um dos grandes símbolos do amor romântico. E nos versos Till I hear the very ash sigh down among the flowers of brass I'll breathe, and long past midnight, your last kiss, ele mostra que quer tardar ao máximo a "presença" do amado "materializado" no cigarro inspirando até o fim a fumaça; e então, com o apagar 
PISETTA, A.; RITCHIE, C.; MILTON, J.; FRANCO, T.; TEIXEIRA, V. Edwin Morgan:...

do cigarro, levar a ponta deste à própria boca "beijando indiretamente" o amado que num momento anterior estivera com o cigarro à boca: your last kiss. Essa conclusão me permitiu ser infiel à literalidade para ser mais fiel à sonoridade: traduzi spire por "anel". Uma opção mais fiel seria "coluna", termo evidentemente mais fálico. No entanto "anel" causa ressonância com breu, sinal, adeus, espiral. Também para manter essa ressonância preferi usar "flores de metal" na tradução de flowers of brass. Insisti na questão da ressonância porque, a meu ver, rimas internas permeiam todo o poema. Por exemplo, as palavras brass, I'll breathe, quando pronunciadas nessa ordem, têm sonoridade próxima a last kiss, num efeito que eu chamaria de "rima impressionista".

Enfim, depois de muito olhar pela janela e não usar quase nada do que havia anotado, escrevi: 


\section{UM CIGARRO}

Meu fogo, sem você não há fumaça.

Você se foi

deixando em meu cinzeiro seu cigarro aceso

e com ele um rastro cinza, silente e teso.

Então sorrio, pois quem veria neste sinal

amor tão manifesto? Quem não fuma

divide com um cigarro o mesmo teto!

E quando o último anel

estremece e sobe, uma lufada súbita

lança sua espiral sobre meu rosto.

É o perfume ou seria o gosto?

É você de novo e me entorpeço no tabaco da sua boca.

Que se apaguem as luzes

e a fumaça repouse no breu.

Até ouvir o último suspiro

da cinza nas flores de metal,

respiro. E no meio da noite, um beijo de adeus. 
PISETTA, A.; RITCHIE, C.; MILTON, J.; FRANCO, T.; TEIXEIRA, V. Edwin Morgan:...

\section{Virna Teixeira}

Neurologista, poeta e tradutora, Virna é uma das maiores divulgadoras da obra de Edwin Morgan no Brasil. Ela conheceu Morgan em uma leitura de poesia em Edimburgo, e o descreve como um homem extremamente culto e sensível, tímido, acolhedor e atencioso com os leitores. O número 13 da revista Coyote trouxe um artigo de Virna sobre o poeta e a Editora UnB deve em breve publicar o livro Na Estação Central, pela coleção "Poetas do Mundo", com poemas de Morgan traduzidos por Virna. Ela é autora dos livros de poesia Visita e Distância, ambos pela Editora 7 Letras.

O escocês Edwin Morgan, segundo o crítico lan Crichton Smith, é um poeta que apresenta duas facetas na sua escrita: uma persona pública, que retrata essencialmente o ambiente urbano à sua volta (particularmente da cidade de Glasgow), a mídia, os meios de comunicação, e uma persona privada, reservada. Essa persona privada pode ser vislumbrada nos poemas de amor de Morgan, de aspecto introspectivo, intimista, que diferem do restante da sua obra. Nesses poemas, Edwin Morgan adota freqüentemente um tom de monólogo, faz uso do you e evita o uso de pronomes possessivos, o que confere um aspecto de ambivalência, de ambigüidade à sua escrita. Essa técnica não permite ao leitor identificar, por exemplo, se o personagem a quem Morgan se refere é homem ou mulher, heterossexual ou homossexual. Outras formas de ocultamento e fragmentação da escrita também podem ser observadas nesses poemas. Esses recursos foram utilizados pelo poeta para manter-se fiel à sua orientação sexual: práticas homossexuais só foram legalizadas na Escócia em 1980 e só tardiamente Morgan revelou ao público sua homossexualidade.

Em muitos poemas de amor de Morgan existe uma atmosfera de solidão, de isolamento, talvez motivados pela necessidade de censura. "One Cigarette", o poema apresentado aqui expres- 
sa, porém, uma solidão feliz, uma espécie de embriaguez amorosa, ausência preenchida pela lembrança do amante que acaba de partir. Se por um lado há ocultamento do gênero do amante, por outro lado o poema revela uma riqueza de imagens fálicas e eróticas para evocá-lo: o cigarro, a linha da fumaça que "deita" no escuro, a cinza do pós-coito, o cinzeiro como um recipiente passivo após o "fogo" do amor carnal, as flores de bronze. "One cigarette" é um exemplo muito interessante para observar também os artifícios e a habilidade do poeta em trabalhar com códigos, em manter certa reserva do público em relação à sua identidade e ao mesmo tempo atingir a sensibilidade de um número maior de leitores. 
PISETTA, A.; RITCHIE, C.; MILTON, J.; FRANCO, T.; TEIXEIRA, V. Edwin Morgan:...

\section{UM CIGARRO}

Não há fumaça sem você, meu fogo.

Quando você partiu, seu cigarro brilhou no meu cinzeiro e enviou uma linha de um cinza tão ordeiro.

Sorri imaginando quem iria acreditar no sinal de tanto amor. Um cigarro no cinzeiro de não-fumante.

Enquanto a última espiral estremece, uma brisa súbita sopra seu caracol no meu rosto.

É o cheiro, é o gosto?

Você está aqui outra vez, e estou bêbado nos seus lábios de tabaco.

Apague a luz.

Deixe a fumaça deitar no escuro.

Até eu escutar a mesma cinza

suspirar entre as flores de bronze

que respirarei, e muito depois da meia-noite, seu último beijo. 


\section{REFERÊNCIAS BIBLIOGRÁFICAS}

MORGAN, Edwin. Collected Poems. Manchester: Carcanet Press, 1990. Collected Translations. Manchester: Carcanet Press, 1996.

RITCHIE, Christianne. Edwin Morgan: o poeta do presente e do futuro. Dissertação apresentada ao Departamento de Letras Modernas da Universidade de São Paulo para a obtenção do grau de Mestre em Literatura de Língua Inglesa. São Paulo, 25 de agosto de 1997.

SMITH, lan Crichton. The public and private Morgan. In: About Edwin Morgan, CRAWFORD, Robert and WHYTE, Hamish, eds. Edinburgh University Press, Edinburgh, 1990.

TEIXEIRA, Virna. De Glasgow a Saturno. In: Revista Coyote, número 13, Iluminuras, Inverno 2005.

WHYTE, Chistopher. 'Now you see it, now you don't': the love poetry of Edwin Morgan. Glasgow Review, issue 2, 1993.

\section{E na internet:}

Página oficial de Edwin Morgan: www.edwinmorgan.com

Espaço dedicado a Edwin Morgan na página da Carcanet Press:

www.carcanet.co.uk/cgi-in/reframe.cgi? app =scribe\&author $=$ morgane\&file $=$ interview $1 . t x t$

Teixeira, Virna. Entreamor: a poesia amorosa de Edwin Morgan. In: Critério - Dossiê Edwin Morgan http://www.revista.criterio.nom.br/ indexmorgan.htm

Página de Virna Teixeira: http://papelderascunho.net/ 
PISETTA, A.; RITCHIE, C.; MILTON, J.; FRANCO, T.; TEIXEIRA, V. Edwin Morgan:...

\section{NOTAS}

1 Último verso do poema "The Second Life", do livro homônimo: "The old coats are discarded. The old ice is loosed. The old seeds are awake. Slip out of darkness, it is time."

2 Esta e boa parte das informações aqui contidas foram obtidas na dissertação de mestrado Edwin Morgan: o poeta do presente e do futuro, escrita por Christianne Ritchie e defendida na USP em 1997.

3 'Now you see it, now you don't': The Love Poetry of Edwin Morgan, de Christopher Whyte. 